\title{
Bigger Bust No Longer on Trend: Malaysians Prefer Moderation in Ideal Female Breast Augmentation
}

\author{
${ }^{1}$ Reconstructive Science Unit, School of Medical Sciences, Universiti \\ Sains Malaysia, Kota Bharu, Malaysia \\ ${ }^{2}$ Hospital Universiti Sains Malaysia, Health Campus, Universiti Sains \\ Malaysia, Kota Bharu, Malaysia \\ ${ }^{3}$ Department of Medical Education, School of Medical Sciences, \\ Universiti Sains Malaysia, Malaysia \\ ${ }^{4}$ Surgical Department, Hospital Angkatan Tentera Tuanku Mizan, \\ Kuala Lumpur, Malaysia \\ Indian J Plast Surg 2021;54:321-326.
}

Muhammad Izzuddin Hamzan ${ }^{1,2,4}$ Wan Azman Wan Sulaiman ${ }^{1,2} \quad$ Nur Nadia Ismail ${ }^{3}$

\author{
Address for correspondence Wan Azman Wan Sulaiman, MD, \\ Reconstructive Science Unit, Hospital Universiti Sains Malaysia and \\ School of Medical Sciences, Universiti Sains Malaysia, Kubang Kerian, \\ Kelantan, 16150, Malaysia (e-mail: wazman@usm.my).
}

\begin{abstract}
Keywords

- ideal breast size ideal areola size aesthetic breast

Background It is important to correctly determine the ideal female breast anatomy and aesthetic proportions in order to prepare for surgery and establish its goals. Leaving the preference to the operating surgeons alone might leave unsatisfactory results, which especially leads to reoperation, quite often in the aspect of breast dimension.

Methods This study was conducted using an online graphic questionnaire. We attempted to seek male and female perspectives toward their preferred ideal female breast size for breast augmentation, in order to provide up-to-date data to assist breast surgeons in attaining satisfactory surgical results.

Results Sixty males and 67 females participated in the study comprising Asian major ethnicities of Malay, Chinese, and Indian. Universally, $46.6 \%$ of men and $53.5 \%$ of women preferred $30 \mathrm{~mm}$ diameter for the most ideal nipple-areola complex (NAC) size. For the perfect bust, they generally favored size C and D cup (37.8\% and 38.5\%, respectively).

Conclusion The majority of women seek natural breast beauty and the longing for an oversized look appears to have infiltrated practice but these assumptions have finally been challenged by these findings.
\end{abstract}

\section{Introduction}

Patients have long desired an augmentation in breast size because of inadequate development, asymmetry, or loss of volume after pregnancy. It is therefore important to define and correctly determine the optimal female breast and aesthetic proportions, in order to prepare for surgery, set targets of surgery, and evaluate surgical outcomes. Leaving the decision to the operating surgeons alone might leave disappointing results, which especially leads to reoperation, quite often in the aspect of breast dimension. ${ }^{1}$

published online

September 16, 2021
DOI https://doi.org/

$10.1055 / \mathrm{s}-0041-1734572$

ISSN 0970-0358
There are, nonetheless, no assessable aesthetic criteria for the breast, certainly owing to its deformability from stance, arm position, and clothing. The female breast is also the most changeable organ in the body, altering with puberty, weight, hormonal balance, gestation, lactation, and natural aging. ${ }^{2}$ Patient contentment should be the pertinent criterion and not what the surgeon deems as natural and normal, either in size and form. ${ }^{3}$ Therefore, this preliminary study is conducted to provide an initial insight into ideal female breast size to assist plastic surgeons and potential patients in deciding their surgical outcome. 


\section{Materials and Methods}

This study was conducted using an online graphic questionnaire at Hospital Universiti Sains Malaysia (HUSM) to seek the most ideally perfect size of female breast and nipple-areola complex (NAC) from the general community and attempt to associate with their sociodemographic. The participants were recruited from a general community in the HUSM compound, which encompasses various ethnicities and social backgrounds via the convenience sampling method. An electronic medium was utilized to prevent unwanted disadvantages with printed paper such as higher cost, stain, and tear. The breast photographs of the questionnaire were drawn on an empty canvas by Photoshop Studio CS4, with various editing tools to attain the various desired qualities. Finally, the portrait drawings were transformed into black and white photographs to remove possible biases, resulting from colors in skin tone. The upper body was presented from the neckline to the lower border of the lower rib to eliminate the probable effect of waist circumference on attractiveness scores.

The NAC component was set to five panels, which were $15 \mathrm{~mm}, 20 \mathrm{~mm}, 30 \mathrm{~mm}, 40 \mathrm{~mm}$, and $45 \mathrm{~mm}$ in diameter, to be the basic framework ( - Fig. $1 \mathrm{~A}$ ). The NAC was cropped out of the created drawing, and size adjustments were made (enlarge and shrink) before it was blended back into the original drawing. For breast size component, commonly, the plastic surgeon interacts with patients seeking breast augmentation, according to the cup size, even though it is not constant with various band sizes. ${ }^{4} \mathrm{~A}$ typical $\mathrm{C}$ cup size has $22.5 \mathrm{~cm}$ of hemicircumference and $7.35 \mathrm{~cm}$ of the nipple to inframammary fold length, and the usual volume to increase one cup size was in the range of 130 to $205 \mathrm{~mL}{ }^{5,6,7}$ For simplicity, breast C cup size was taken as approximately $500 \mathrm{~mL}$ volume for a guideline, although it was recognized that it may vary among individuals of the same cup due to alterations in the underband size and various breast implant brands. ${ }^{7-9}$ Thus, this component was set to six panels, which were size A: $100 \mathrm{~mL}, \mathrm{~B}: 300 \mathrm{~mL}, \mathrm{C}: 500 \mathrm{~mL}$, D: $700 \mathrm{~mL}$, DD: $900 \mathrm{~mL}$, and E: $1100 \mathrm{~mL}$, to be the basic framework (- Fig. 1 B).
Similarly, the breasts were cropped out of the created drawing and manipulated (resize, enlarge, and shrink) before the breasts were melded back into the original drawing. These photographs were drawn from the front view to demonstrate the size of both breasts in the erect position. Other body features such as the position of the NAC and the body shape remained consistent to prevent assessment bias to different shapes of the torso (e.g., body mass index [BMI]). The photograph panels of each component were piled on each other and displayed as one screen page, and the explicit labels (e.g., $30 \mathrm{~mm}$, size C cup) were hidden to prevent selection bias. The participants were asked to select only one photograph that has the most attractive look of all panels for both NAC and breast size components. Descriptive analysis was conducted to define the preference of an ideal NAC and breast size. By using STATA 15, Fischer's exact test was employed for each association of breast components and its sociodemographic.

\section{Results}

Sixty-eight men and 67 women participated in the survey. The mean age was 34.67 years. Fifty-five participants (40.7\%) were between the ages 18 to 29 years, 59 participants (43.7\%) were between the ages 30 to 49 years, and 21 participants (15.6\%) were between the ages 50 years and above. There was an identical proportion of the main racial component of Malay, Chinese, and Indian (31.1\%). Twenty-seven participants $(20.0 \%)$ worked in the health care sector (-Table 1).

The highest proportion of NAC size and breast size preferred among the participants was $30 \mathrm{~mm}$ (43.0\%) and breast size D cup (37.8\%), respectively (-Table 2 ). There was no significant association between NAC size and their sociodemographic (-Table 3). From the Fischer's exact test, there was a significant association between breast size and gender ( $p$ $=0.023$ ), with those preferring $\mathrm{D}$ cup being higher among males compared with females (59.6\% vs. $40.4 \%)$, whereas those preferring $C$ cup being higher among females compared with males ( $62.8 \%$ vs. $37.3 \%)$. There was no significant association found between other demographics and breast
A
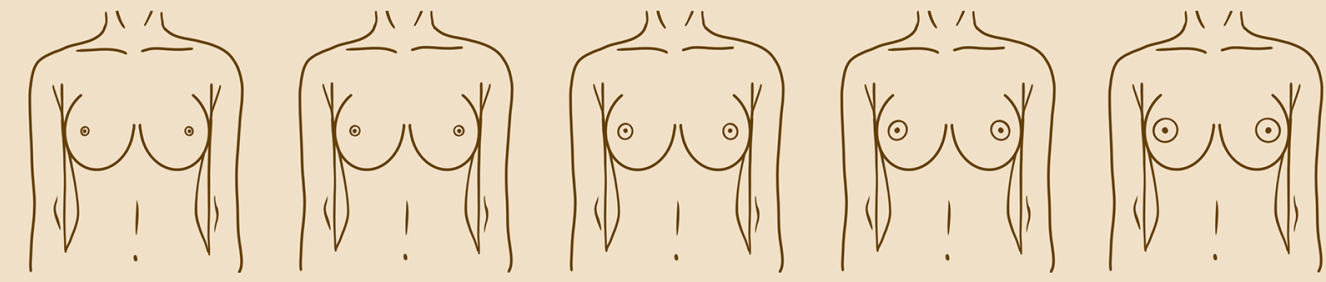

B
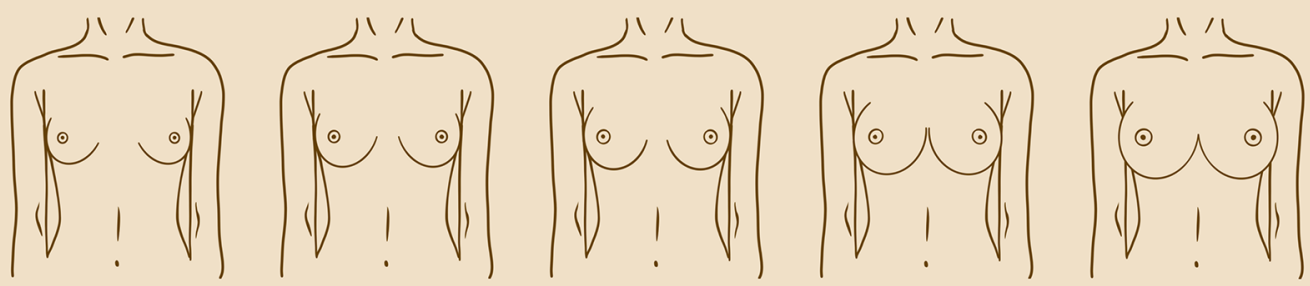

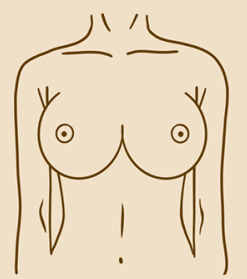

Fig. 1 Drawn image panel from front view showing from the left. (A) The size of nipple-areola complex (NAC) 15 mm, $20 \mathrm{~mm}, 30 \mathrm{~mm}, 40 \mathrm{~mm}$, and $45 \mathrm{~mm}$; (B) the breast size cup A, B, C, D, DD, and E. 
size (-Table 4). It was noted that most of the Malays and Chinese preferred breast size $C$ cup, while Indians were more inclined to a D cup size. Younger participants (18-29 years old) favored the C cup, similar to most of the single individuals, whereas the 30 to 49 years group preferred the D cup, like the majority of married individuals.

\section{Discussion}

Although the judgment of an individual's perception concerning aesthetic value is greatly influenced by continuous observations and their concept of beauty and perfectness, it remains unclear to what amount it is conditioned by age, gender, race, and cultural background..$^{10} \mathrm{~A}$ structured review of the literature assessing the perfect breast by Rubano in 2019 agreed that no clear formula to create the "ideal" breast exists and therefore appropriate discussion must happen between surgeons and patients to understand the artistic aesthetic and its linear measurements which constitute patient's ideal breast. ${ }^{11}$ In considering ideal breast shape,

Table 1 Descriptive analysis of sociodemographic of the participants $(n=135)$

\begin{tabular}{|l|l|}
\hline Variable & Frequency (\%) \\
\hline Age (years) & $34.67(12.00)$ \\
\hline Age group (years) & \\
\hline $18-29$ & $55(40.7)$ \\
\hline $30-49$ & $59(43.7)$ \\
\hline$\geq 50$ & $21(15.6)$ \\
\hline Gender & \\
\hline Male & $67(49.6)$ \\
\hline Female & $68(50.4)$ \\
\hline Race & \\
\hline Malay & $42(31.1)$ \\
\hline Chinese & $42(31.1)$ \\
\hline Indian & $42(31.1)$ \\
\hline Others & $9(6.7)$ \\
\hline Education level & \\
\hline Primary/secondary & $49(36.3)$ \\
\hline Tertiary & $75(55.6)$ \\
\hline Postgraduate level & $11(8.2)$ \\
\hline Occupation & $24(17.8)$ \\
\hline Unemployed & $62(45.9)$ \\
\hline Self-employed & $60(44.4)$ \\
\hline Retired & \\
\hline Health care sector & \\
\hline Nonhealth care sector & \\
\hline Marital status & $27.0)$ \\
\hline Single & \\
\hline Married & \\
\hline Widower & \\
\hline
\end{tabular}

Table 2 Descriptive analysis of ideal breast preferences $(n=135)$

\begin{tabular}{|l|l|}
\hline Breast appearance & Frequency (\%) \\
\hline NAC size in diameter (mm) & \\
\hline 15 & $13(9.6)$ \\
\hline 20 & $37(27.4)$ \\
\hline 30 & $58(43.0)$ \\
\hline 40 & $21(15.6)$ \\
\hline 45 & $6(4.4)$ \\
\hline Breast size & \\
\hline Size A cup & $5(3.7)$ \\
\hline Size B cup & $12(8.9)$ \\
\hline Size C cup & $51(37.8)$ \\
\hline Size D cup & $52(38.5)$ \\
\hline Size DD cup & $9(6.7)$ \\
\hline Size E cup & $6(4.4)$ \\
\hline
\end{tabular}

Abbreviation: NAC, nipple-areola complex.

certainly patient fulfillment should be the important touchstone and not the natural look. ${ }^{12}$ Henceforth, these findings should illustrate the basic underlying variations of desired breast shape ( size) across demographics, redefining expectations of breast appeal.

The size of the NAC is one of the vital characteristics in defining the attractiveness of the breast. ${ }^{10}$ Owing to its striking border and appealing contrast that rise at the center of the mount, it is not only easily recognized but also rendered as the apparent feature that makes up a beautiful breast as a whole. The accepted standard areola size has been classically set at 38 to $45 \mathrm{~mm} .{ }^{1}$ In our finding, universally (43\%), $46.6 \%$ of men and $53.5 \%$ of women across all ethnicities preferred $30 \mathrm{~mm}$ diameter as the ideally perfect NAC ( - Fig. 2 A), which was in accordance with the previous anthropometric study done locally. ${ }^{13}$ However, it was slightly different to Westerners, wherein the ideal size was 35 to $45 \mathrm{~mm} .{ }^{12}$ This is most probably due to the distinctive topographical and racial distribution between these two opposing continents. These findings showed consistency in the eastern part of the globe; if not East Asia, at least Malaysia where the participant demographic comprises the majority ethnicities found in Asia (Malay, Chinese, and Indian), although from the same nationality. This was similarly presented recently in another study of ideal breast perception in Asia, albeit the population was only from China, Korea, and Japan (common ancestry), with the exclusion of Malay Archipelago and Indian lineage. ${ }^{14}$

Throughout history, women seem to accentuate the look of their breasts, with large bust considered the supreme beauty in many cultures, which has been associated with exceptional fertility compared with regular sizes. ${ }^{10}$ Furthermore, the oversizing consequences are well-recognized and are among the typical reasons for their reduction. ${ }^{15}$ Therefore, breast size is one of the critical features affecting attractiveness. For perfect female bust, 
Table 3 Association between areola size and sociodemographic $(n=135)$

\begin{tabular}{|c|c|c|c|c|c|c|}
\hline \multirow[t]{2}{*}{ Sociodemographic factor } & \multicolumn{5}{|c|}{ Areola size, n (\%) } & \multirow[t]{2}{*}{$p$-value } \\
\hline & $15 \mathrm{~mm}(n=13)$ & $20 \mathrm{~mm}(n=37)$ & $\begin{array}{l}30 \mathrm{~mm} \\
(n=58)\end{array}$ & $\begin{array}{l}40 \mathrm{~mm} \\
(n=21)\end{array}$ & $\begin{array}{l}45 \mathrm{~mm} \\
(n=6)\end{array}$ & \\
\hline \multicolumn{7}{|l|}{ Age group (years) } \\
\hline $18-29$ & $6(46.2)$ & $12(32.4)$ & $22(37.9)$ & $10(47.6)$ & $5(83.3)$ & 0.479 \\
\hline $30-49$ & $4(30.8)$ & $17(46.0)$ & $28(48.3)$ & $9(42.9)$ & $1(16.7)$ & \\
\hline$\geq 50$ & $3(23.1)$ & $8(21.6)$ & $8(13.8)$ & $2(9.5)$ & $0(0.0)$ & \\
\hline \multicolumn{7}{|l|}{ Gender } \\
\hline Male & $10(76.9)$ & $21(56.8)$ & $27(46.6)$ & $7(33.3)$ & $2(33.3)$ & 0.106 \\
\hline Female & $3(23.1)$ & $16(43.2)$ & $31(53.5)$ & $14(66.7)$ & $4(66.7)$ & \\
\hline \multicolumn{7}{|l|}{ Race } \\
\hline Malay & $7(53.9)$ & $10(27.0)$ & $17(29.3)$ & $7(33.3)$ & $1(16.7)$ & 0.093 \\
\hline Chinese & $3(23.1)$ & $16(43.2)$ & $20(34.5)$ & $3(14.3)$ & $0(0.0)$ & \\
\hline Indian & $2(15.4)$ & $10(27.0)$ & $17(29.3)$ & $10(47.8)$ & $3(50.0)$ & \\
\hline Others & $1(7.7)$ & $1(2.7)$ & $4(6.9)$ & $1(4.8)$ & $2(33.3)$ & \\
\hline \multicolumn{7}{|l|}{ Occupation } \\
\hline Unemployed & $0(0.0)$ & $6(16.2)$ & $12(20.7)$ & $4(19.1)$ & $2(33.3)$ & 0.380 \\
\hline Self-employed & $1(7.7)$ & $8(21.6)$ & $8(13.8)$ & $1(4.8)$ & $0(0.0)$ & \\
\hline Retired & $1(7.7)$ & $3(8.1)$ & $1(1.7)$ & $1(4.8)$ & $0(0.0)$ & \\
\hline Health care sector & $4(30.8)$ & $5(13.5)$ & $9(15.5)$ & $7(33.3)$ & $2(33.3)$ & \\
\hline Nonhealth care sector & $7(53.9)$ & $15(40.5)$ & $28(48.3)$ & $8(38.1)$ & $2(33.3)$ & \\
\hline \multicolumn{7}{|l|}{ Marital status } \\
\hline Single & 7 (53.9) & $21(56.8)$ & $29(50.0)$ & $10(47.6)$ & $4(66.7)$ & 0.966 \\
\hline Married & $6(46.2)$ & $15(40.5)$ & $28(48.3)$ & $11(52.4)$ & $2(33.3)$ & \\
\hline Widower & $0(0.0)$ & $1(2.7)$ & $1(1.7)$ & $0(0.0)$ & $0(0.0)$ & \\
\hline
\end{tabular}

${ }^{a}$ Expected count of less than 5 was $\geq 20 \%$; Fisher exact test was applied.

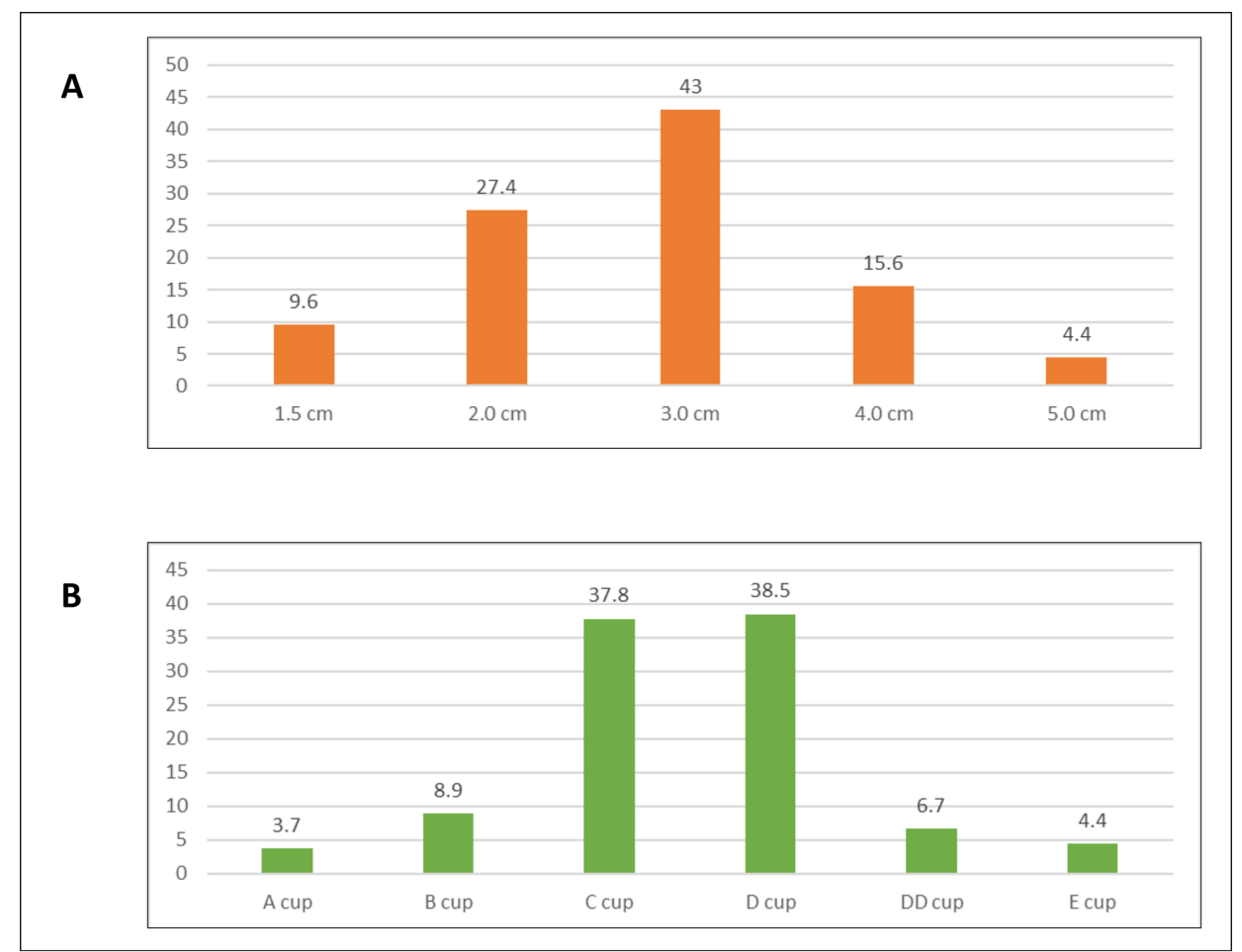

Fig. 2 (A) Most preferred nipple-areola complex (NAC) size in percentage among the participants; (B) most preferred breast size in percentage among the participants. 
Table 4 Association between breast size and sociodemographic $(n=135)$

\begin{tabular}{|c|c|c|c|c|c|c|c|}
\hline \multirow[t]{2}{*}{ Sociodemographic factor } & \multicolumn{6}{|c|}{ Breast size, $n(\%)$} & \multirow[t]{2}{*}{$p$-value } \\
\hline & $\begin{array}{l}\text { A cup } \\
(n=5)\end{array}$ & $\begin{array}{l}\text { B cup } \\
(n=12)\end{array}$ & $\begin{array}{l}\text { C cup } \\
(n=51)\end{array}$ & $\begin{array}{l}\text { D cup } \\
(n=52)\end{array}$ & $\begin{array}{l}\text { DD cup } \\
(n=9)\end{array}$ & $\begin{array}{l}\text { E cup } \\
(n=6)\end{array}$ & \\
\hline \multicolumn{8}{|l|}{ Age group (years) } \\
\hline $18-29$ & $1(20.0)$ & $8(66.7)$ & $25(49.0)$ & $18(34.6)$ & $2(22.2)$ & $1(16.7)$ & 0.175 \\
\hline $30-49$ & $2(40.0)$ & $3(25.0)$ & $17(33.3)$ & $28(53.9)$ & $5(55.6)$ & $4(66.7)$ & \\
\hline$\geq 50$ & $2(40.0)$ & $1(8.3)$ & $9(17.7)$ & $6(11.5)$ & $2(22.2)$ & $1(16.7)$ & \\
\hline \multicolumn{8}{|l|}{ Gender } \\
\hline Male & $4(80.0)$ & $3(25.0)$ & $19(37.3)$ & $31(59.6)$ & $5(55.6)$ & $5(83.3)$ & 0.023 \\
\hline Female & $1(20.0)$ & $9(75.0)$ & $32(62.8)$ & $21(40.4)$ & $4(44.4)$ & $1(16.7)$ & \\
\hline \multicolumn{8}{|l|}{ Race } \\
\hline Malay & $2(40.0)$ & $3(25.0)$ & $20(39.2)$ & $12(23.1)$ & $3(33.3)$ & $2(33.3)$ & 0.447 \\
\hline Chinese & $0(0.0)$ & $5(41.7)$ & $18(35.3)$ & $16(30.8)$ & $2(22.2)$ & $1(16.7)$ & \\
\hline Indian & $2(40.0)$ & $4(33.3)$ & $12(23.5)$ & $19(36.5)$ & $3(33.3)$ & $2(33.3)$ & \\
\hline Others & $1(20.0)$ & $0(0.0)$ & $1(1.96)$ & $5(9.6)$ & $1(11.1)$ & $1(16.7)$ & \\
\hline \multicolumn{8}{|l|}{ Education level } \\
\hline Primary/secondary & $2(40.0)$ & $4(33.3)$ & $25(49.0)$ & $12(23.1)$ & $4(44.4)$ & $2(33.3)$ & 0.293 \\
\hline Tertiary & $3(60.0)$ & $7(58.3)$ & $24(47.1)$ & $33(63.5)$ & $5(55.6)$ & $3(50.0)$ & \\
\hline Postgraduate & $0(0.0)$ & $1(8.3)$ & $2(3.9)$ & 7 (13.5) & $0(0.0)$ & $1(16.7)$ & \\
\hline \multicolumn{8}{|l|}{ Occupation } \\
\hline Unemployed & $0(0.0)$ & $4(33.3)$ & $8(15.7)$ & $9(17.3)$ & $2(22.2)$ & $1(16.7)$ & 0.300 \\
\hline Self-employed & $2(40.0)$ & $2(16.7)$ & $9(17.7)$ & $3(5.8)$ & $1(11.1)$ & $1(16.7)$ & \\
\hline Retired & $0(0.0)$ & $0(0.0)$ & $4(7.8)$ & $2(3.9)$ & $0(0.0)$ & $0(0.0)$ & \\
\hline Health care sector & $1(20.0)$ & $2(16.7)$ & $15(29.4)$ & $7(13.5)$ & $1(11.1)$ & $1(16.7)$ & \\
\hline Nonhealth care sector & $2(40.0)$ & $4(33.3)$ & $15(29.4)$ & $31(59.6)$ & $5(55.6)$ & $3(50.0)$ & \\
\hline \multicolumn{8}{|l|}{ Marital status } \\
\hline Single & $1(20.0)$ & $7(58.3)$ & $30(58.8)$ & $27(51.9)$ & $3(33.3)$ & $3(50.0)$ & 0.515 \\
\hline Married & $4(80.0)$ & $5(41.7)$ & $19(37.3)$ & $25(48.1)$ & $6(66.7)$ & $3(50.0)$ & \\
\hline Widower & $0(0.0)$ & $0(0.0)$ & $2(3.9)$ & $0(0.0)$ & $0(0.0)$ & $0(0.0)$ & \\
\hline
\end{tabular}

aExpected count of less than 5 was $\geq 20 \%$; Fisher exact test was applied.

generally, participants preferred size C and D cup (37.8\% and $38.5 \%$ respectively) (-Fig. $\mathbf{2}$ B), with most of the men (59.6\%) favoring larger size D cup and women (62.8\%) opting for C cup. Based on ethnicities, Malay and Chinese preferred C cup (28.1\%), whereas Indians preferred larger size D cup (14\%). A previous local study on anthropometric ideal breast corresponded to this result, whereby the ideal size was approximated to the C cup. ${ }^{13}$ Meanwhile, DD and E cup is enormous, an indication to seek reduction, hence the lower number in proportion. Among anthropometric studies on ideal breast, the mean breast volume for Turkish women was $407.2 \mathrm{~mL}$, while among Malaysian women, the values of the right and left breast volumes were $553.38 \mathrm{~mL}$ and $536.59 \mathrm{~mL}$, respectively. ${ }^{13,16}$ For Korean women, the mean volume was $386.0 \mathrm{~mL}$ for the right breast and $393.3 \mathrm{~mL}$ for the left breast. ${ }^{17}$ In studies of perception, male preferences for female breast size seem to be greatly variable. Among the Sudanese Azande, men preferred long pendulous breasts; the Alorian men of Alor Island in Indonesia favored large breasts; and the men of the Kenyan Massai tribes preferred firm upright breasts. ${ }^{18}$ Universally, $40 \%$ of men and $25 \%$ of women favored large breasts across different cultures and ethnicities, and most studies executed on ideal breasts emphasized size, with the finding that men from Western regions prefer medium or big breasts, while in Malaysia, men with a low socioeconomic society considered bigger breasts 
to be more attractive. ${ }^{19-21}$ By comparison, plastic surgeons preferred breast size D cup, which demonstrated universal consistency within the population. ${ }^{22}$ In general, more men than women preferred a larger female breast across different cultures and ethnicities, mainly Caucasians, Asians, and African-Americans, including this study. ${ }^{19,23,24}$

Although NAC and breast size are among the essentials affecting aesthetics, yet the key factor is not just an explicit size, but rather a shape and body proportions. It is believed only breast size in proportion to the body will find attractiveness. The authors identified some limitations in this preliminary study which prohibit it from achieving a more substantial result. Chiefly contributing to these restrictions is the sample size. From the technical perspective, the questionnaire can be developed via three-dimensional (3D) photographs, with features of rotation, pan, and zoom to enhance and accurately assess the "size" in 3D plane perspective. The use of an interactive online questionnaire enhances user practice and is easier to operate. Authors realized that the perception of beauty is somewhat confounded subjectively and heavily persuaded by time, trend, and media which can be potentially altered. Nonetheless, authors feel the quest to search for ideal attributes in aesthetic female breasts is preeminent in this age to suit the current need, although these values might be shifted in the near future. Therefore, with this preliminary result, researchers would have a new idea to drive a more comprehensive study, in order to extend its confirmation, relevance, and significance.

\section{Conclusion}

The majority of women seek perfect breast, and the aspiration for an oversized look has finally been challenged by these findings. In this present day, people, in general, prefer moderation in size, that is, neither too big nor too small to be the most perfect female breast shape and which can assist a plastic surgeon in counseling patients for breast augmentation surgery.

\section{Source of Funding}

None

\section{Conflict of interests}

None declared

\section{Acknowledgments}

We appreciate the journal for granting us the opportunity to work with them.

\section{References}

1 Atiye B, Chahine F. Metrics of the aesthetically perfect breast. Aesthetic Plast Surg 2018;42(5):1187-1194

2 Brody GS. The perfect breast: is it attainable? Does it exist? Plast Reconstr Surg 2004;113(5):1500-1503

3 Liu YJ, Thomson JG. Ideal anthropomorphic values of the female breast: correlation of pluralistic aesthetic evaluations with objective measurements. Ann Plast Surg 2011;67(1):7-11
4 McGhee DE, Steele JR. Breast volume and bra size. Int J Cloth Sci Technol 2011;23(5):351-360

5 Vandeput JJ, Nelissen M. Considerations on anthropometric measurements of the female breast. Aesthetic Plast Surg 2002;26(5):348-355

6 Bengtson BP, Glicksman CA. The standardization of bra cup measurements: redefining bra sizing language. Clin Plast Surg 2015;42(4):405-411

7 King NM, Lovric V, Parr WCH, Walsh WR, Moradi P. What is the standard volume to increase a cup size for breast augmentation surgery? A novel three-dimensional computed tomographic approach. Plast Reconstr Surg 2017;139(5):1084-1089

8 Choppin SB, Wheat JS, Gee M, Goyal A. The accuracy of breast volume measurement methods: a systematic review. Breast 2016;28:121-129

9 McGhee DE, Steele JR. How do respiratory state and measurement method affect bra size calculations. ? Br J Sports Med 2006;40(12):970-974

10 Broer PN, Juran S, Walker ME, et al. Aesthetic breast shape preferences among plastic surgeons. Ann Plast Surg 2015;74(6):639-644

11 Rubano A, Siotos C, Rosson GD, Manahan MA. The notion of the ideal breast and its variability: Reviewing the difficulty of perceiving beauty through defined margins. Breast J 2019;25(5):938-941

12 Swanson E, Evidence-Based Cosmetic Breast Surgery. Cham, Switzerland: Springer International; 2017

13 Selvaprahasam US. A study on anthropometric breast measurements in the Malay population in Malaysian women. Master's thesis, Universiti Sains Malaysia; 2014

14 Lee HJ, Ock JJ. An ideal female breast shape in balance with the body proportions of Asians. Plast Reconstr Surg Glob Open 2019;7(9):e2377

15 Mallucci P, Branford OA. Population analysis of the perfect breast: a morphometric analysis. Plast Reconstr Surg 2014;134(3):436-447

16 Avşar DK, Aygit AC, Benlier E, Top H, Taşkinalp O. Anthropometric breast measurement: a study of 385 Turkish female students. Aesthet Surg J 2010;30(1):44-50

17 Kim SJ, Kim M, Kim M-J. The affecting factors of breast anthropometry in Korean women. Breastfeed Med 2014;9(2):73-78

18 Dixson BJ, Vasey PL, Sagata K, Sibanda N, Linklater WL, Dixson AF. Men's preferences for women's breast morphology in New Zealand, Samoa, and Papua New Guinea. Arch Sex Behav 2011;40(6):1271-1279

19 Prantl L, Gründl M. Males prefer a larger bust size in women than females themselves: an experimental study on female bodily attractiveness with varying weight, bust size, waist width, hip width, and leg length independently. Aesthetic Plast Surg 2011;35(5):693-702

20 Groyecka A, Żelaźniewicz A, Misiak M, Karwowski M, Sorokowski P. Breast shape (ptosis) as a marker of a woman's breast attractiveness and age: Evidence from Poland and Papua. Am J Hum Biol 2017;29(4):1-8

21 Swami V, Tovée MJ. Resource security impacts men's female breast size preferences. PLoS One 2013;8(3):e57623

22 Hamzan MI, Wan Sulaiman WA, Ismail NN. Breast size for aesthetic surgery: preference from plastic surgeons in Malaysia. Eur J Plast Surg 2021;(e-pub ahead of print). doi: 10.1007/s00238-021-01787-4

23 Kościński K. Breast firmness is of greater importance for women's attractiveness than breast size. Am J Hum Biol 2019;31(5):e23287

24 Tantleff-Dunn S. Breast and chest size: ideals and stereotypes through the 1990s. Sex Roles 2001;45(3-4):231-242 